\title{
A Q-Theoretic approach to distinctive subsegmental timing
}

Karee Garvin, Myriam Lapierre \& Sharon Inkelas*

\begin{abstract}
This paper presents two case studies of segment-internal timing distinctions which motivate $\mathrm{Q}$ Theory, in which each segment $(\mathrm{Q})$ is represented as a string of featurally uniform subsegments (q), e.g. (q1 q2 q3), corresponding to the informal concepts of onset, target, and offset (Inkelas \& Shih 2013, 2016, 2017, Shih \& Inkelas 2014). We argue, based on Panará and Hungarian, that this representational richness is motivated by the need to represent phonologically tripartite segments, as well as segment-internal timing distinctions that are phonologically contrastive. In addition to supporting existing Q Theory architecture, we also argue for expanding the repertoire of Q Theory further to include phonologically long segments, such as geminates.
\end{abstract}

Keywords. phonology; subsegmental representations; Q Theory; contour segments; geminates; partially-nasalized consonants

1. Background. Subsegmental representations are of long-standing interest in phonology, as evidenced by the very large body of literature discussing them (among many others, Goldsmith 1976, Leben 1978, Pulleyblank 1986, Sagey 1986, Hayes 1990, Lombardi 1990, Steriade 1993, 1994, 1995, Kehrein \& Golston 2004).

A major landmark proposal in this literature, Aperture Theory (Steriade 1993, 1994) is a model of bipartite subsegmental representations that was proposed specifically to account for complex stops and affricates. According to this model, stops and affricates have two distinct phonological phases, namely stop closure $\left(\mathrm{A}_{0}\right)$ and stop release $\left(\mathrm{A}_{\max }\right)$, whereas vowels, approximants, and fricatives have a single position in their segmental representation. This model of the subsegment is particularly well suited to representing prenasalized and postnasalized stops, as in (1) (Steriade 1993).
a. [nas]
$\mathrm{A}_{0} \mathrm{~A}_{\max }$
Prenasalized
b. [nas]
$\mathrm{A}_{0} \mathrm{~A}_{\max }$
Postnasalized
c. $[$ nas]
$\wedge$
$\begin{array}{ll}\mathrm{A}_{0} \mathrm{~A}_{\max } & \mathrm{A}_{0} \mathrm{~A}_{\max } \\ \text { Nasal stop } & \text { Oral stop }\end{array}$

In example (1a), the closure phase of the stop $\left(\mathrm{A}_{0}\right)$ is linked to a privative nasal feature, which results in a prenasalized stop; in $(1 \mathrm{~b})$, only the release phase $\left(\mathrm{A}_{\max }\right)$ is linked to a nasal feature, which results in a postnasalized stop; in (1c), both the closure and release phases are linked to a nasal feature, which results in a fully nasalized stop; and in (1d), neither the closure nor the release phase is linked to a nasal feature, such that the resulting stop is fully oral.

While Aperture Theory provides crucial machinery for representing bipartite segments, a large body of subsequently compiled evidence indicates that two subsegments is in fact not sufficient to capture the level of granularity for the detail of subsegmental information permitted by human languages (among many others, see Akinlabi \& Liberman 2001, Hyman 2007, Kim 2008,

\footnotetext{
* We thank audiences at UC Berkeley's Phonetics and Phonology Forum and at the Linguistic Society of America meeting in Salt Lake City for insightful feedback on earlier presentations of this work. We would also like to thank the Panará community for allowing us to study their language, Anne Pycha for discussion and access to her original Hungarian data, and Susan Lin for help in processing the Panará phonetics data.
} 
Tadmor 2009, Operstein 2010, Pycha 2010, Remijsen 2013, Remijsen \& Ayoker 2014). Specifically, three subsegments appears to be the necessary level of granularity, and as such, we embrace Q Theory, a model of the segment comprised of three (rather than two) subsegments.

Q Theory takes segmental decomposition one step further than Aperture Theory did, dividing segmental representations into three subsegments (Shih \& Inkelas 2014; Inkelas \& Shih 2016, 2017, forthcoming, Schwarz et al. 2017), as in (2). The large [Q] represents the level of the segment, and the three small q's $\left(\mathrm{q}^{1} \mathrm{q}^{2} \mathrm{q}^{3}\right)$ represent the three subsegments $(2 \mathrm{a})$, which can be seen as three temporally ordered feature bundles. Each $q$ has its own phonological feature specification; phonetic values between each small $\mathrm{q}$ are obtained through interpolation.

The necessity for a tripartite subsegmental representation is immediately apparent in the case of prenasalized affricates, which have three clearly distinct phases. The representation of a prenasalized affricate is provided in (2b) (Shih \& Inkelas 2014; Inkelas \& Shih 2016, 2017).
a. [Q]
b. [nts]
$\left(\mathrm{q}^{1} \mathrm{q}^{2} \mathrm{q}^{3}\right)$
$\left(n^{1} t^{2} s^{3}\right)$

2. Road map. This paper is organized as follows: $\S 3$ provides novel evidence for a tripartite representation of the segment from circumoralized nasal stops, $\S 4$ provides a summary of the architecture of Q Theory, $\S 5$ presents an overview of proposed Q-theoretic representations with less than three subsegments and an expansion of the model for geminate consonants using four and five subsegments, $\S 6$ presents a case study on Hungarian affricates, and $\S 7$ concludes with a summary and reflection on the scope of Q Theory.

3. Evidence for a tripartite representation. In this section, we introduce novel evidence in favor of a tripartite representation of the segment, focusing on circumoralized nasal consonants in two Amazonian languages: Karitiâna (Tupí, Brazil) and Kaingang (Jê, Brazil). Both Karitiâna and Kaingang possess a contrast in oral and nasal vowels, as well as a series of phonemically nasal consonants, namely /m, n, $\mathrm{n}, \mathrm{y} /$. These nasal consonants undergo partial oralization when they occur immediately before or after a phonemically oral vowel, as in Table $1^{1}$. Phonemically nasal consonants are realized as fully nasal only when they occur adjacent to nasal vowels and/or word boundaries (a). They are realized as post-oralized when they occur before an oral vowel (b); they are realized as preoralized when they occur after an oral vowel (c); and, crucially for our argument in support of Q Theory, they are realized as circumoralized when they occur between two oral vowels $(\mathrm{d})$.

Karitiâna (Storto 1999) Kaingang (Wiesemann 1972)

\begin{tabular}{|c|c|c|c|c|}
\hline a. $/ \mathrm{m} / \rightarrow[\mathrm{m}] /\{\tilde{\mathrm{V}}, \#\}$ & ãmãท & to plant & mõmæ̃̄y & fear \\
\hline b. $/ \mathrm{m} / \rightarrow[\mathrm{mb}] /\{\tilde{\mathrm{V}}, \#\}$ & ãmbo & to climb & $\phi \tilde{m m b u}$ & tobacco \\
\hline c. $/ \mathrm{m} / \rightarrow[\mathrm{bm}] / \mathrm{V}$ & hibmĩnã & roasted & habmæ̃ & to listen \\
\hline d. $/ \mathrm{m} / \rightarrow[\mathrm{bmb}] / \mathrm{V}$ & apibmbik & to pierce & kebmba & to try out \\
\hline
\end{tabular}

Table 1: Partially nasalized consonants in Karitiâna (Tupí) and Kaingang (Jê)

\footnotetext{
${ }^{1}$ For reasons of space, we only provide examples for underlying /m/, but the partial oralization process described here applies for the entire series of nasal consonants.
} 
In her exposition of this data, Storto (1999) states that the behavior of tripartite nasal stops in Karitiâna are not readily amenable to a bipartite model of the segment. In order to capture circumoralization using the binary architecture afforded by Aperture Theory, Storto observes, it is necessary to resort to associating one of the two possible phases of a stop -- Storto selects the closure -- with two different, sequenced values of the nasal feature, as in (3).

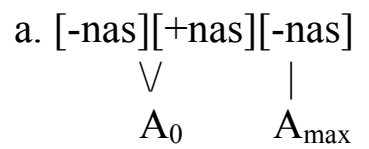

While necessary within the strictures of Aperture Theory, this hybrid proposal requires two theoretical sacrifices: the inability to continue treating [nasal] as a privative feature, and a regression to the many-to-one association between features and timing slots that characterized Autosegmental Phonology. Thus, while completely motivated, this proposal within Aperture Theory reintroduces the original geometry that Aperture Theory intended to replace and one of the original problems that Aperture Theory intended to resolve.

By contrast, employing a Q-Theoretic tripartite representation of the segment solves the dilemma Storto faced and allows for a straightforward and elegant representation of circumoralized nasal stops in Karitiâna and Kaingang, as in (4), where $b^{1}$ and $b^{3}$ have feature bundles corresponding to [b], and $\mathrm{m}^{2}$ has the feature bundle corresponding to [m].

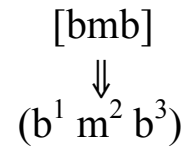

4. Architecture of $\mathbf{Q}$ Theory. In this section we take a closer look at key architectural elemetns of Q Theory that are relevant for our exposition of complex segments in Panará and Hungarian. Covering all the details of the architecture of Q Theory falls outside of the scope of this paper; for a more detailed exposition of Q Theory machinery, we refer the reader to (Shih \& Inkelas 2014; Inkelas \& Shih 2016, 2017, forthcoming).

Q Theory's conceptual design incorporates key aspects of both Aperture Theory and Articulatory Phonology (Browman \& Goldstein 1989, 1990, 1992, Gafos 2002). The 'Q' in Q Theory stands for 'quantized.' $Q$ Theory, like Aperture Theory, affords a quantized representation of the subsegment. The three subsegments of Q Theory roughly ${ }^{2}$ correspond to the gestural phase landmarks of Articulatory Phonology, namely onset, target, and offset. This correspondence is illustrated in Figure 1, where 1 refers to the gesture onset, i.e. the movement towards the articulatory target; 2 refers to the target; and 3 refers to the offset, i.e. the movement away from the target.

\footnotetext{
2 The correspondence between subsegments and gestural phase landmarks is more transparently applicable for some segment types (e.g., stops) than for others.
} 


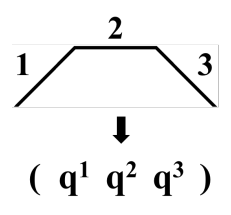

Figure 1. Rough correspondence between the articulatory phases of Articulatory Phonology and the quantized subsegments of Q Theory

Three subsegments is the maximum number of subsegments for a segment of average duration, such as a plain stop. Segments may have fewer than three subsegments, as in the case of flaps and some epenthetic segments, and they may have more than three subsegments if they are phonologically long, both of which will be discussed in $\S 5$. Note that the superscript numbers of the subsegments should be interpreted as relative, rather than absolute. This notion will be particularly important in expanding the machinery of Q Theory to phonologically long segments, such as geminates, also discussed in $§ 5$.

Given its incorporation of notions of Articulatory Phonology, such as gestural overlap, Q Theory affords us a quantized phonological model of coarticulation, as schematically illustrated in Figure 2 for the Kaingang word [kebmba] 'to try out' (data from Wiesemann 1972).

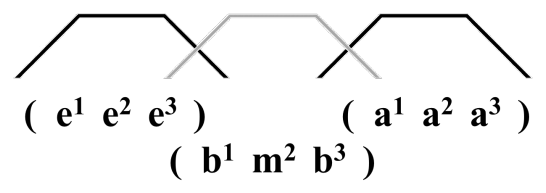

Figure 2. Schematic representation of Q Theory as a quantized model of coarticulation

The black lines in Figure 2 correspond to the key gestures, specifically tongue position and state of the velum, required to produce the vowels [e] and [a]. The gray line in the middle corresponds to the gestures required to produce the circumoralized nasal stop [bmb]. Specifically, $\mathrm{q}^{3}$ of the first vowel [e] (i.e., $\mathrm{e}^{3}$ ) and $\mathrm{q}^{1}$ of the medial stop (i.e., $\mathrm{b}^{1}$ ) overlap temporally, as do $\mathrm{q}^{3}$ of the medial stop (i.e., $b^{3}$ ) and $\mathrm{q}^{1}$ of the following vowel [a] (i.e., $\mathrm{a}^{1}$ ). In this example, the velic opening gesture begins after the preceding vowel gesture has completely finished, such that the nasal stop is preoralized by virtue of coarticulation of the orality of the preceding vowel onto the consonant. The velic closing gesture also begins before the onset of the following vowel, such that the stop is also postoralized.

Given its formalization of a tripartite representation of the segment, Q Theory allows for finer grained descriptive power, predicting segment types that were not possible in previous models of phonology. Circumoralized consonants are among these; so is the contrast between post-oralized and prenasalized stops, to which we turn next.

In their overview paper on partially nasalized consonants, Maddieson and Ladefoged (1993) state the following: "There [...] seem to be several ways in which [postoralized] nasals differ from prenasalized stops in the phonetic domain [...], but it is less clear that distinct phonological structures are in volved. We know of no language in which these two classes of sounds contrast with each other. [...] The lack of phonological distinction between these two is well predicted by Steriade's theory of aperture positions." The paper from which this quote is taken was published in the same volume as Steriade's (1993) original paper on Aperture Theory, and in fact supports the bipartite model of subsegmental representations of the time. A segmental representating permitting only two featurally distinct subphases of a segment predicts the lack of 
contrast that Maddieson and Ladefoged identify.. In comparison, Q Theory's tripartite representation of the segment allows us to make the prediction that, in fact, such a contrast is possible in languages. As we show, this prediction of Q Theory is borne out by data from Panará (Jê, Brazil).

Panará provides evidence of a contrast between prenasalized oral stops [ ${ }^{\mathrm{m}} \mathrm{p}$ ] and postoralized nasal stops $\left[\mathrm{m}^{\mathrm{p}}\right]$. Panará, like Karitiâna and Kaingang, exhibits a contrast between oral and nasal vowels, as well as a series of contrastively nasal stops at four places of articulation (Lapierre \& Bardagil, ms.). Nasal consonants in Panará are only ever fully nasalized when they occur before nasal vowels, as in (5a). Postoralized nasal stops appear as allophones of nasal stops when they occur before approximants or phonemically oral vowels, as in (5b). Prenasalized stops also appear as allophones of oral stops when they follow a phonemically nasal vowel, as in $(5 \mathrm{c})$.
a. $/ \mathrm{m}, \mathrm{n}, \mathrm{n}, \mathrm{y} / \rightarrow[\mathrm{m}, \mathrm{n}, \mathrm{n}, \mathrm{y}] / \tilde{\mathrm{V}}$
b. $/ \mathrm{m}, \mathrm{n}, \mathrm{n}, \mathrm{y} / \rightarrow\left[\mathrm{m}^{\mathrm{p}}, \mathrm{n}^{\mathrm{t}}, \mathrm{n}^{\mathrm{s}}, \mathrm{n}^{\mathrm{k}}\right] / 2-\{\mathrm{V}, \mathrm{w}, \mathrm{r}, \mathrm{j}\}$
c. $/ \mathrm{p}, \mathrm{t}, \widehat{\mathrm{ts}}, \mathrm{k} / \rightarrow\left[{ }^{\mathrm{m}} \mathrm{p},{ }^{\mathrm{n}} \mathrm{t},{ }^{\mathrm{n}} \mathrm{s},{ }^{\mathrm{n}} \mathrm{k}\right] / \tilde{\mathrm{V}}$

Thus in the environment $\tilde{V}_{-} V$, i.e. between a nasal and oral vowel, nasal stops surface as postoralized $\left[\mathrm{m}^{\mathrm{p}}\right]$, while oral stops surface as prenasalized $\left[{ }^{\mathrm{m}} \mathrm{p}\right]$. The two are not neutralized: $\left[{ }^{\mathrm{p}} \mathrm{m}\right]$ and $\left[\mathrm{m}^{\mathrm{p}}\right]$ are distinct. Phonetic data provides evidence that the duration of nasality in postoralized nasals like $\left[\mathrm{m}^{\mathrm{p}}\right](5 \mathrm{~b})$ is greater than the duration of nasality in prenasalized oral stops $\left[{ }^{\mathrm{m}} \mathrm{p}\right](5 \mathrm{c})$, such that the two processes that result in surface NC sequences do not in fact result in contrast neutralization. The phonetic data in question come from acoustic and nasal and oral airflow data collected by the second author from three male speakers of Panará. A total of 211 tokens of postoralized nasal stops, and 124 tokens of prenasalized oral stops, were collected (for a full analysis of this data, we refer the reader to Lapierre, ms.). The average total duration of postoralized nasal stops was $274.1 \mathrm{~ms}$, and the average total duration of prenasalized oral stops was $261.3 \mathrm{~ms}$. The average duration of nasality in postoralized nasal stops was $133.6 \mathrm{~ms}$, which is a proportion of $48.7 \%$ of the total duration of the $\mathrm{NC}$, and the average duration of nasality in prenasalized oral stops was $101.5 \mathrm{~ms}$, which is a proportion of $38.9 \%$ of the total duration of the NC. These results are presented in Figure 3, which shows the proportion duration of nasality in postoralized nasal stops and prenasalized oral stops.

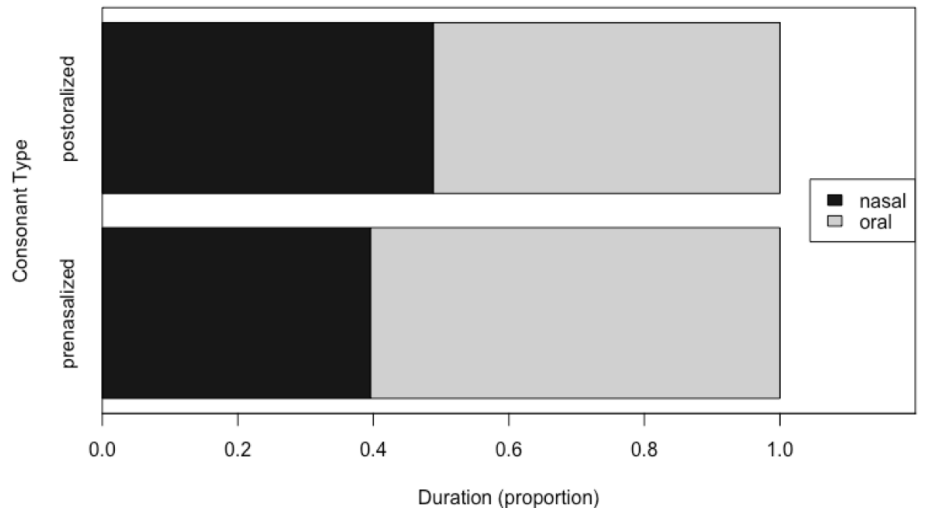

Figure 3. Duration proportion of nasality in postoralized nasal stops vs. prenasalized oral stops

The duration data was submitted to a one-tailed Welch t-test, which showed that the duration of nasality in postoralized nasal stops is significantly greater than the duration of nasality in prenasalized oral stops $(\mathrm{p}<.001, \mathrm{t}=7.9596, \mathrm{df}=245.05)$. Given the statistically significant difference between the two kinds of partially nasalized stops in Panará, we propose that the post- 
oralized nasal stops and prenasalized oral stops have different Q-theoretic representations, as shown in (6). Specifically, the postoralized nasal stops $\left[\mathrm{m}^{\mathrm{p}}\right]$ are represented with two [m] subsegments and one [p] subsegment (6a), while the prenasalized oral stops $\left[{ }^{\mathrm{m}} \mathrm{p}\right]$ are represented with one [m] subsegment and two [p] subsegments (6b).

(6)
a. $\quad\left[\mathrm{m}^{\mathrm{p}}\right]$

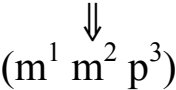
Postoralized nasal
b. $\left[{ }^{\mathrm{m}} \mathrm{p}\right]$<smiles>[CH]=C</smiles>

$$
\left(\mathrm{m}^{1} \mathrm{p}^{2} \mathrm{p}^{3}\right)
$$
Prenasalized oral

These data from Panará partially nasalized consonants provide a straightforward example of predictions that Q Theory allows us to make and test. Of course, with the greater richness of Q Theory, and the possibility of making predictions that were not possible with other phonological models of subsegmental representations, comes the question of whether the range of predicted structures afforded by Q Theory is too powerful. We believe that this is not the case. Like segmental and Autosegmental Phonology before it, Q Theory has the capacity represent segments that are unattested (so far) in human languages. But Q Theory is also constrainable by the same mechanisms that constrain other models of segments, such as articulatory constraints and the Pmap (Steriade 2008). For example, such principles can be invoked to explain why circumoralized nasal stops $\left[{ }^{b} \mathrm{~m}^{\mathrm{b}}\right]$ exist, while hypothetical circumnasalized oral stops $\left[{ }^{\mathrm{m}} \mathrm{b}^{\mathrm{m}}\right]$ do not. Both are technically representable in Q Theory. However, the oral closure of a circumnasalized oral stop would not be perceptually salient enough to become phonologized, and thus circumnasalized oral stops $\left[{ }^{\mathrm{m}} \mathrm{b}^{\mathrm{m}}\right]$ can be ruled out by P-map constraints that prevent segment inventories from containing two segments that are perceptually too indistinct from one another.

5. Expanding the model. While the null hypothesis is that segments have three subsegments, certain scenarios motivate representations with fewer or greater than three subsegments. These include excrescent segments, unreleased segments, and geminates. This section motivates the proposal that different numbers of subsegments are needed to account for different types of segments and provides examples of how these segments might be represented.

5.1. REPRESENTATIONS WITH FEWER THAN THREE SUBSEGMENTS. Inkelas and Shih (2016) introduce Q-theoretic representations of excrescent segments and flaps, both of which are arguably best represented with fewer than three subsegments. We turn first to excrescent vowels, which are the result of low gestural overlap between the release of one subsegment and the onset of the next. The openness of the vowel tract during this brief transition results in an excrescent vowel (Gafos 2002, Hall 2003). Gafos (2002:273) provides an example from Moroccan Colloquial Arabic in which the sequence $[\mathrm{mn}]$ is produced with an excrescent vowel as $\left[\mathrm{m}^{\curvearrowright} \mathrm{n}\right]$.

\section{(7) $\left[\operatorname{smim}^{\curvearrowright} n\right]$ 'fat.diminuative' (cf. [smim] 'fat')}

As shown in Figure 4, the gestural gap between the release of the [m] and the onset of the following $[\mathrm{n}]$ in this form results in a short, epenthetic schwa-like vowel.

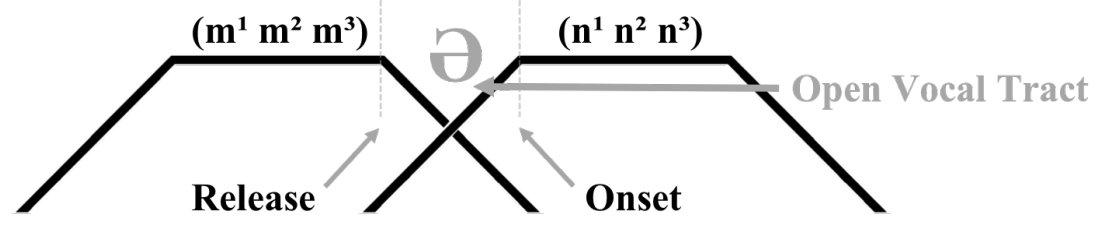

Figure 4. Schematic representation of excrescent vowel 
The acoustics of excrescent segments are dependent on their neighboring segments and disappear in fast speech conditions. Additionally, by definition, these segments are shorter than other vowels in duration and never bear stress. Inkelas and Shih (2016) argue that the relatively short duration of epenthetic segments can be captured in a Q-theoretic representation in the form of a single subsegment, as shown in (8).

$$
\begin{gathered}
{\left[\mathrm{m}^{\ominus} \mathrm{n}\right]} \\
\Downarrow \\
\left(\mathrm{m}^{1} \mathrm{~m}^{2} \mathrm{~m}^{3}\right) \partial\left(\mathrm{n}^{1} \mathrm{n}^{2} \mathrm{n}^{3}\right)
\end{gathered}
$$

In this example, both [m] and [n] are full segments and, as such, are represented with three subsegments and contained within parentheses, the formal symbolic demarcation of the segment in Q Theory. The excrescent schwa-like vowel in (8) is a single subsegment positioned between two full consonantal segments. Crucially, excrescent vowels are not contained in parentheses, as these epenthetic vowels do not possess the phonological status of a full segment. In this manner, Q-theory provides a quantized representation of the articulatory facts presented by Gafos (2002). Inkelas and Shih (2016) also hypothesize that similar representations are appropriate for emergent consonants such as the epenthetic [t] that results between the sequence [ns].

Much like excrescent segments, the phonetic properties of a flap also motivate a phonological representation that is more impoverished, subsegmentally, than that of other 'full' segments. Phonologists have struggled to adequately represent the unique phonetic properties of flaps. As discussed by Inkelas and Shih (2016), Hayes (2009) treats flaps as sonorant, consonantal continuants and argues for the addition of the phonological feature [+flap]. These features are effective at rendering flap unique from /. $/$. However, Mielke (2004) argues that classifying flaps as either stops or continuants is difficult, and that this representation is therefore unsatisfactory. Given that flaps are by nature short and lack a steady state target, Q Theory offers a straightforward representation of flaps in which there is no "target" subsegment: a flap consists only of transitional subsegments, as in (9). This two-subsegment representation captures the inherent properties of the flap and provides a representation which is distinct from that of other consonants, drawing on the flexible architecture of Q Theory.

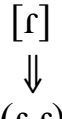

( 1 r)

Gussenhoven (1986), Kahn (1976) and others have argued that in American English, flaps are ambisyllabic. This property is captured especially elegantly in Q Theory, in which the two subsegments of a flap can be assigned to either side of the syllable boundary The lack of a 'target' medial subsegment in the Q Theoretic representation of a flap accords with speakers' intuitions that the flap belongs inherently to neither syllable.

Ambisyllabicity is of course not restricted to flaps, but is also possible with other segment types, as demonstrated in the examples in (10), provided by Inkelas and Shih (2016).

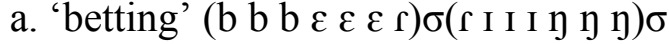
b. 'carry' (k k h $\varepsilon \varepsilon \varepsilon \mathrm{I}) \sigma(\mathrm{I} . \mathrm{I}$ i i i $) \sigma$

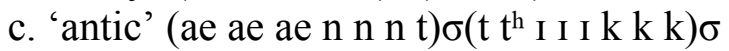


Inkelas and Shih (2016) suggest that, although standard phonological theory holds that syllabification operates on full segments, insight can be gained by allowing syllabification to operate on the more granular level afforded by subsegmental representations in Q Theory.

In sum, there is much to be gained in allowing the fine-grained, subsegmental architecture of Q Theory to represent segments with fewer than three subsegments, such as excrescent segments and flaps. Conversely, Q Theory also permits the expansion of segments to four or more subsegments, a possibility whose merits we assess in the next subsction.

3.2. REPRESENTATIONS WITH MORE THAN THREE SUBSEGMENTS. Geminate consonants provide an excellent testing ground for the hypothesis that a phonologically long segment (either underlyingly long or lengthened through the application of a phonological process) may support a representation with more than three subsegments. Geminates are by definition longer than singletons, though phonetically their duration is typically not double that of singletons. Geminates typically have a similar internal featural structure to their singleton counterparts; the transition into a geminate and the release of that geminate is typically the same as the transitional portions of a singleton. It is characteristically the closure phase of a geminate that is extended durationally and, arguably, ambisyllabic.

Standard autosegmental representations of geminates use two timing units associated with a single feature bundle. While effective at capturing the ambisyllabicity of geminate consonants, such representations fail to capture the fact that it is the closure, specifically, that is extended under gemination. By contrast, Q Theory has the descriptive sensitivity to represent both the durational and the articulatory properties of gemination. We offer, as a starting point, the representation in (11).

$$
\begin{gathered}
{[\mathrm{t}:]} \\
\Downarrow \Downarrow \\
\left(\mathrm{t}^{1} \mathrm{t}^{2} \mathrm{t}^{2} \mathrm{t}^{3}\right)
\end{gathered}
$$

This four-part representation maintains the initial and final subsegments as transitional subsegments and extends (by doubling) the closure, i.e. $\mathrm{t}^{2}$, subsegmental portion. While $\mathrm{Q}$ Theory is not designed or intended to represent absolute durational differences, this representation does accurately captures the relative timing differences between singletons and geminates: the latter are lengthened, not doubled per se.

A characteristic property of geminate consonants is their ambisyllabic nature. As discussed above, Q Theory offers a simple method for capturing ambisyllabicity. We propose as a default that the closure of a geminate extends across the syllable boundary. Given that there are two closure segments in the Q-theoretic representation, the syllable boundary thus is naturally represented between the two $\mathrm{t}^{2}$ subsegments representing the closure of the geminated stop, as in (12).

$$
\begin{gathered}
{[\mathrm{t}:]} \\
\left(\mathrm{t}^{1} \mathrm{t}^{2} \cdot \mathrm{t}^{2} \mathrm{t}^{3}\right)
\end{gathered}
$$

Given this representation, the portion of the geminate in each syllable exactly matches the singleton components of heterosyllabic consonant clusters with an unreleased transition, in which an unreleased segment is represented as $\left(\mathrm{t}^{1} \mathrm{t}^{2}\right)$ (Inkelas \& Shih, 2016, building on Steriade's related proposals in Aperture Theory). 
6. Case Study: Hungarian Geminates. In this section, we present a case study of Hungarian geminate affricates that illustrates the potential for the expansion of the machinery of Q Theory to capture not only the contrast between singletons and geminates but also the behavior of singletons under phonological lengthening processes.

The introduction of Q-Theoretic representations with more than three subsegments predicts the existence of contrasts that rely on the representations this expansion brings. We find such a case in Hungarian, where Pycha has argued that a segment-internal timing distinction across two types of affricates is maintained under gemination.

Pycha $(2009,2010)$ discusses relative timing differences between the closure and fricative portions of [ts] and [t $\left.\int\right]$ in Hungarian, where [t] has a longer closure in [t $\left.\int\right]$ than in [ts]. Inkelas and Shih (2016) proposed a Q-theoretic representation for these segments, as shown in (13).
(13) a. [ts]
b. $[\mathrm{t} f]$

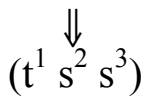
$\left(\mathrm{t}^{1} \mathrm{t}^{2} \int^{3}\right)$

Pycha $(2009,2010)$ explains that this same distinction in relative stop-fricative durations holds under gemination, in which the frication portion of the affricate remains the same but and the duration of the closure is extended. Crucially, while this same pattern holds under phonological gemination, it does not hold in phonetic lengthening conditions. In Hungarian, phrase final segments are longer than in other contexts. In this phonetic lengthening condition, the portion of the segment nearest the boundary is lengthened. This means that the fricative portion of the affricate is lengthened, rather than the closure portion. Figure 5, adapted from Pycha 2009, demonstrates these relative timing differences.

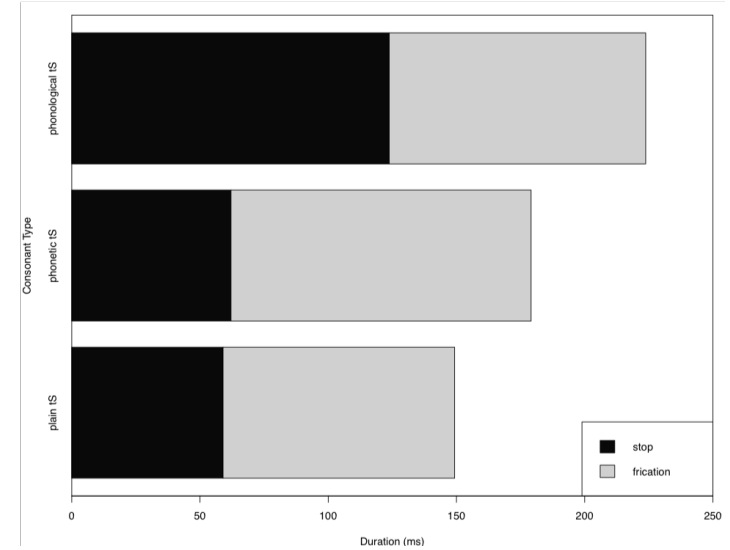

Figure 5. Duration proportion of closure and frication of Hungarian affricates for singletons and phonetic and phonological lengthening conditions based on data from Pycha (2009)

As shown in Figure 5, the closure timing of a plain affricate and its phonetically lengthened counterpart is approximately the same, whereas the frication portion for the phonetically lengthened affricate is significantly longer than that of its singleton counterpart. On the other hand, the frication portion for the phonologically lengthened geminate is approximately equivalent to the singleton, whereas the closure portion of the phonological geminate is significantly longer than the closure portion of the singleton. This difference in whether the stop or fricative portion of an affricate is lengthened can be interpreted as follows: the relative segment-internal timing differences of [ts] and [t $\mathrm{t}]$ affricates in Hungarian are maintained in phonological lengthening, but not in phonetic lengthening. This suggests that the internal structure of affricates has 
been phonologized. This fact motivates representing the internal structure of geminate affricates subsegmentally, as Q Theory permits.

A Q-theoretic representation of geminate contours must build upon both the representation of the singleton contour and the non-contour geminates. Like the non-contour geminates, the Qtheoretic representation of contour geminates should represent the durational patterns and the syllabification of geminates. Like the singleton contour segments, the geminate contour segments should capture the relative timing differences between the Hungarian affricates [ts] and [t $\left.\int\right]$. The framework demonstrated in $\S 3$ for representing geminates and the representation discussed by Inkelas and Shih (2016) provides a clear path for representing Hungarian geminate affricates in Q Theory, as in (14).
(14) a. (tss:)
$\Downarrow$
b. $\quad\left(\mathrm{tt} \int:\right)$
$(\mathrm{t} t \mathrm{t}$ s s)
$\left(\mathrm{tt} . \mathrm{tt} \int\right)$

The heterosyllabic geminate affricate representations in (14) have the virtue that the material on each side of the syllable boundary looks exactly like a singleton stop would in the same position. Prior to the syllable boundary, the representation is identical to that of an unreleased [ $\mathrm{t}^{\urcorner}$], lacking a final release subsegment. Following the syllable boundary, the representation is the same as representation of the the singleton affricate: the closure is maintained across the syllable. This representation captures the lengthening of the closure and heterosyllabicity of gemination while maintaining the contrast between the two types of affricates.

The motivation for wanting to capture the representation of the internal structure of these segments lies in two main points. First, the relative timing of affricates is consistent for singletons and is maintained for phonological geminates, indicating that the relative timing is a phonologized property of the segment. Second, phonological lengthening, i.e., gemination, maintains these relative timing differences where phonetic lengthening does not. If the timing properties were a function of inherent timing of segments, we would not expect there to be a difference for phonetical vs phonetic lengthening, a point also argued by Pycha. Because the relative timing of these affricates is phonologized, it should be captured in phonological representations. Q Theory provides the representational power to fully capture these contrasts.

Hungarian provides one example of the importance of the subsegmental representations afforded by Q Theory; however, this is an area that has only just began to be explored. We expect that a great many more contrasts of the type Pycha explored in Hungarian exist in the world's languages. Q Theory not only predicts such contrasts to exist but provides the descriptive adequacy needed to explore the space of possible contrasts.

7. Conclusion. This paper has provided a programmatic overview of the architecture of Q Theory and proposed an expansion to the Q Theory as developed to date (Shih \& Inkelas 2014; Inkelas \& Shih 2016, 2017, forthcoming, Schwarz et al. 2017). In its essence, Q Theory formalizes the idea that segments $(Q)$ are maximally composed of three subsegments $\left(q^{1} q^{2} q^{3}\right)$. This model allows for subsegmental representations that capture the internal structure of contour segments. Furthermore, it makes predictions about the types of contours that we expect languages to contrast, as demonstrated by the data presented from Karitiâna (Tupí), Kaingang (Jê), and Panará (Jê).

In addition, $\mathrm{Q}$ Theory makes predictions about the behavior of segment-internal structure under phonological processes, as demonstrated by the Hungarian data analyzed by Pycha. In particular, our discussion of gemination suggests that, the existing architecture of Q Theory can 
be extended to representations with more than three subsegments, not just to representations with fewer than three subsegments, as proposed by Inkelas and Shih (2016).

While it may be argued that Q Theory makes unattested predictions about the possible segments and contrasts observed in the world's languages, we argue that the same principles that constrain other theories of phonology, e.g. P-map and articulatory constraints, constrain Q Theory. Furthermore, while we have argued for the place of phonological length in q-theoretic representations, we do not propose that Q-theoretic representations should account for absolute representations. Absolute durations are dependent on speech rate and a variety of other factors including intrinsic segment quality, making phonological representations of absolute duration unrealistic and an unreasonable and unnecessary task for the phonologist. In particular, we have argued here for representations relevant to attested contrasts within a language, and representations of absolute durations do not offer the same benefit. Finally, we note that subsegmental representations are not the right level of granularity for all problems. This is why the segmental, or Q, level is also available in Q Theory's machinery.

Q-theory has clear advantages in allowing for phonological representations of segments and subsegments that account for a range of phonological phenomena, including contour segments, e.g., partially nasalized stops and affricates, as well as the relative timing of segments e.g., excrescent segments, flaps, and geminates. Thus, when subsegmental differences obtain, a Q-theoretic subsegmental representation is arguably the best available phonological tool for capturing them.

\section{References}

Akinlabi, Akin \& Mark Liberman. 2001. Tonal complexes and tonal alignment. In Minjoo Kim \& Uri Strauss (eds.), Proceedings of the North East Linguistic Society 31(1). 1-20. Amherst, MA: GLSA Publications.

Browman, Catherine P. \& Louis Goldstein. 1989. Articulatory Gestures as Phonological Units. Phonology 6(2). 201-251.

Browman, Catherine P. \& Louis Goldstein. 1990. Tiers in Articulatory Phonology, with some implications for casual speech. In John Kingston \& Mary Beckman (eds.), Papers in Laboratory Phonology I: Between the Grammar and Physics of Speech. 341-376. Cambridge: Cambridge University Press.

Browman, Catherine P. \& Louis Goldstein. 1992. Articulatory Phonology: an overview. Phonetica 49. 155-180.

Gafos, Adamantios I. 2002. A grammar of gestural coordination. Natural Language \& Linguistic Theory 20(2). 269-337.

Goldsmith, John. 1976. An Overview of Autosegmental Phonology. Linguistic Analysis 2. 22-68.

Gussenhoven, Carlos. 1986. English Plosive Allophones and Ambisyllabicity. Gramma 10(2). 119-141.

Hall, Nancy E. 2003. Gestures and segments: Vowel intrusion as overlap. Amherst, MA: University of Massachusetts dissertation.

Hayes, Bruce. 1990. Diphthongization and coindexing. Phonology 7(1). 31-71.

Hayes, Bruce. 2009. Introductory Phonology. Wiley-Blackwell.

Hyman, Larry M. 2007. Universals of tone rules: 30 years later. In Tomas Riad and Carlos Gussenhoven (eds.) Tones and tunes: studies in word and sentence prosody. 1-34. Berlin: Mouton de Gruyter. 
Inkelas, Sharon \& Stephanie S. Shih. 2016. Re-representing phonology: consequences of Q Theory. In Christopher Hammerly \& Brandon Prickett (eds.), Proceedings of the North East Linguistic Society 46. GLSA Publications.

Inkelas, Sharon \& Stephanie S. Shih. 2017. Looking into Segments. In Karen Jesney, Charlie O'Hara, Caitlin Smith \& Rachel Walker (eds.), Proceedings of the 2016 Annual Meeting on Phonology. Washington, DC: Linguistic Society of America.

Kahn, Daniel. 1976. Syllable-based generalizations in English phonology. Cambridge, MA: MIT dissertation.

Kehrein, Wolfgang \& Chris Golston. 2004. A prosodic theory of laryngeal contrasts. Phonology 21. 325-357. http://doi.org/10.1017/S0952675704000302

Kim, Yuni. 2008. Topics in the phonology and morphology of San Francisco del Mar Huave. Berkeley, CA: University of California dissertation.

Lapierre, Myriam. (in prep.) Patterns of nasal coarticulation in Panará. UC Berkeley ms.

Lapierre Myriam \& Bernat Bardagil-Mas. (in prep.) A phonological analysis of Panará. UC Berkeley ms.

Leben, William R. 1978. The representation of tone. In Victoria Fromkin (ed.), Tone: A Linguistic Survey. 177-219. New York: Academic Press.

Lombardi, Linda. 1990. The nonlinear organization of the affricate. Natural Language \& Linguistic Theory 8(3). 375-425.

Mielke, Jeff. 2004. The emergence of distinctive features. Columbus, OH: The Ohio State University dissertation.

Maddieson, Ian \& Peter Ladefoged. 1993. Phonetics of Partially Nasal Consonants. In Marie K. Huffman, \& Rena A. Krakow, Phonetics and Phonology 5: Nasals, nasalization, and the velum, 251-301. London: Academic Press.

Operstein, Natalie. 2010. Consonant structure and prevocalization. Amsterdam/Philadelphia: John Benjamins Publishing Company.

Pulleyblank, Douglas. 1986. Tone in Lexical Phonology. Springer, Netherlands: Kluwer Academic Publishers.

Pycha, Anne. 2009. Lengthened affricates as a test case for the phonetics phonology interface. Journal of the International Phonetic Association 39. 1-31.

Pycha, Anne. 2010. A test case for the phonetics-phonology interface: Gemination restrictions in Hungarian. Phonology 27. 119-152.

Remijsen, Bert. 2013. Tonal alignment is contrastive in falling contours in Dinka. Language 89. 297-327.

Remijsen, Bert. \& Otto G. Ayoker. 2014. Contrastive tonal alignment in falling contours in Shilluk. Phonology 31(3). 435-462.

Sagey, Elizabeth C. 1986. The Representation of features and Relations in Non-Linear Phonology. Cambridge, MA: MIT dissertation.

Shih, Stephanie S. \& Sharon Inkelas. 2014. A subsegmental correspondence approach to contour tone (dis)harmony patterns. In John Kingston, Claire Moore-Cantwell, Joe Pater \& Amanda Rysling (eds.), Proceedings of the 2013 Meeting on Phonology. Washington, DC: Linguistic Society of America.

Shih, Stephanie S. \& Sharon Inkelas. Forthcoming. Autosegmental aims in surface optimizing phonology. To appear in Linguistic Inquiry.

Stanton, Juliet. 2017. Constraints on the Distribution of Nasal-Stop Sequences: An Argument for Contrast. Cambridge, MA: MIT dissertation. 
Steriade, Donca. 2008. The Phonology of Perceptibility Effects: The P-Map and Its Consequences for Constraint Organization. In Kristin Hanson \& Sharon Inkelas (eds.), The Nature of the Word: Essays in Honor of Paul Kiparsky. 151-178. Cambridge, MA: MIT Press.

Steriade, Donca. 1993. Closure, release and nasal contours. In Marie Huffman \& Loren Trigo (eds.), Phonetics and Phonology 5: Nasals, nasalization and the velum. 401-470.

Steriade, Donca. 1994. Complex Onsets as Single Segments: The Mazateco Pattern. In Jennifer S. Cole \& Charles W Kisseberth (eds.), Perspectives in phonology. 203-291. CSLI Publications, Stanford.

Steriade, Donca. 1995. Underspecification and markedness. In John Goldsmith (ed.), The handbook of phonological theory. 114-174. Cambridge, MA: Blackwell Publishers.

Storto, Luciana R. 1999. Aspects of Karitiana Grammar. Cambridge, MA: MIT dissertation.

Tadmor, Uri. 2009. Developing an orthography for Onya Darat (Western Borneo). Wacana 11(2). 279-293.

Wiesemann, Ursula. 1972. Die phonologische und grammatische Struktur der Kaingang Sprache. The Hague: Mouton. 